\title{
Desain Rotor Bawah Air Untuk Memanfaatkan Laju Aliran Sungai Sebagai Pembangkit Listrik Tenaga Air
}

\author{
${ }^{(1)^{*}}$ Rendi, ${ }^{(2)}$ Budi Hatradi, ${ }^{3}$ Muhammad Irfansyah , ${ }^{(4)}$ Puteri \\ ${ }^{(1)(2)(3)(4)}$ Program Studi Teknik Mesin, Universitas Islam Kalimantan Jl. Adhyaksa No. 2 Kayi Tangi \\ Banjarmasin Kalimantan Selatan \\ *Email: rendi.teknikmesin@gmail.com
}

Diterima: 07.09.2021 Disetujui: 19.10.2021 Diterbitkan: 24.10.2021

\begin{abstract}
This study aims to design an underwater rotor to utilize the flow rate of the river as a hydroelectric power plant. In this study, an underwater rotor design model will be made with three variations in the number of blades, namely three blades, six blades and nine blades. The test parameter observed in this study is the turbine performance through the value of the power coefficient (cp) and the moment coefficient (cm). The method used in this research is an experimental method, namely by making a turbine model with a laboratory scale. The results show that the underwater rotor designed with aspect ratio $=2.0$, overlap ratio $=0$ and end-plate diameter $=1.1 \mathrm{~d}$ then the barrier plate design with $L / D$ ratio $=1.260^{\circ}$ provides the highest power coefficient and moment coefficient, namely respectively 0.15 and 0.27 in the design with the number of blades 3 (three)
\end{abstract}

Keywords: Design, Underwater rotor, Variation in Number of Blades

\begin{abstract}
ABSTRAK
Penelitian ini bertujuan untuk membuat desain rotor bawah air untuk memanfaatkan laju aliran sungai sebagai pembangkit listrik tenaga air. Dalam penelitian ini akan dibuat satu model desain rotor bawah air dengan tiga variasi jumlah sudu yaitu sudu tiga, sudu enam dan sudu sembilan. Parameter uji yang diamati dalam penelitian ini adalah kinerja turbin melalui nilai koefesien tenaga (cp) dan koefesien momen $(\mathrm{cm})$. metode yang digunakan dalam penelitian ini adalah metode eksperimen yaitu dengan membuat model turbin dengan skala labolotarium. Hasil penelitian menunjukan bahwa rotor bawah air yang didesain dengan aspect ratio $=2.0$, overlap ratio $=0$ dan diameter end-plate $=1,1 \mathrm{~d}$ kemudian desain plat penghalang dengan rasio $L / D=1.2 \Theta \leq 60^{\circ}$ memberikan koefesien tenaga dan koedesien momen tertingi yaitu berturut-turut 0.15 dan 0.27 pada desain dengan jumlah sudu 3 (tiga)
\end{abstract}

Kata Kunci: Desain, Underwater rotor, Variasi Jumlah Sudu

\section{Pendahuluan}

Dalam beberapa tahun terakhir, energi posil semakin hari semakin menipis sementara penggunaan energi posil semakin tahun semakin bertambah hal ini menuntut para ilmuan dan para peneliti untuk mengembangkan energi baru dan terbarukan. (Rendi \& Hartadi, 2018). Salah satu energi baru dan terbarukan yang marak di kembangkan saat ini adalah energi aliran air sungai ini tidak terlepas dari energi ini sangat melimpah di alam namun punya karakteristik yang berbeda dengan energi- energi baru dan terbarukan lainnya seperti energi panas bumi, energi surya, energi angin dan energi gelombang laut.(Rendi, Ihsan, et al., 2020)

Energi aliran sungai bisa diubah menjadi energi listrik dengan bantuna peralatan mekanik seperti turbin air yang sekarang ini banyak di lakukan oleh masyarakat namun yang menjadi permasalahannya turbin air pada umumnya bekerja dengan kecepatan aliran air yang cepat dan memiliki hed air yang besar.(Rendi \& Arifin, 2019) \&(Rendi, Arifin, et al., 2020)

Alliran air khususnya di Indosensia cendrung beraliran lambat yaitu kecepatan air sungai berkisar dibawah $1 \mathrm{~m} / \mathrm{s}$ (hasil pengujian pada beberapa sungai di Kalimantan Selatan) 
dan punya head rendah tentu ini tidak memungkinkan untuk dipasang turbin air jika tidak dilakukan pembendungan. Sementara untuk melakukan pembendungan memerlukan biaya yang sangat besar dan dapat merusak lingkungan sekitar bendungan.(Rendi \& Sidiq, 2018) \&(Rendi, 2017). Solusi alternatif yang ditawarkan untuk mengatasi permasalahan adalah dengan membuat turbin air yang dapat bekerja di aliran lambat. Pada penelitian ini kami menawarkan Underwater Rotor. Underwater Rotor adalah turbin air yang di desain bekerja dibawah air sehingga tidak terpengaruh banjir atau surutnya air dan mampu bekerja di aliran lambat.

Penelitian ini bertujuan untuk membuat desain rotor bawah air untuk memanfaatkan laju aliran sungai sebagai pembangkit listrik tenaga air.

\section{Bahan dan Metode}

Gambar 1 menunjukan tahapan-tahapan desain Underwater rotor.

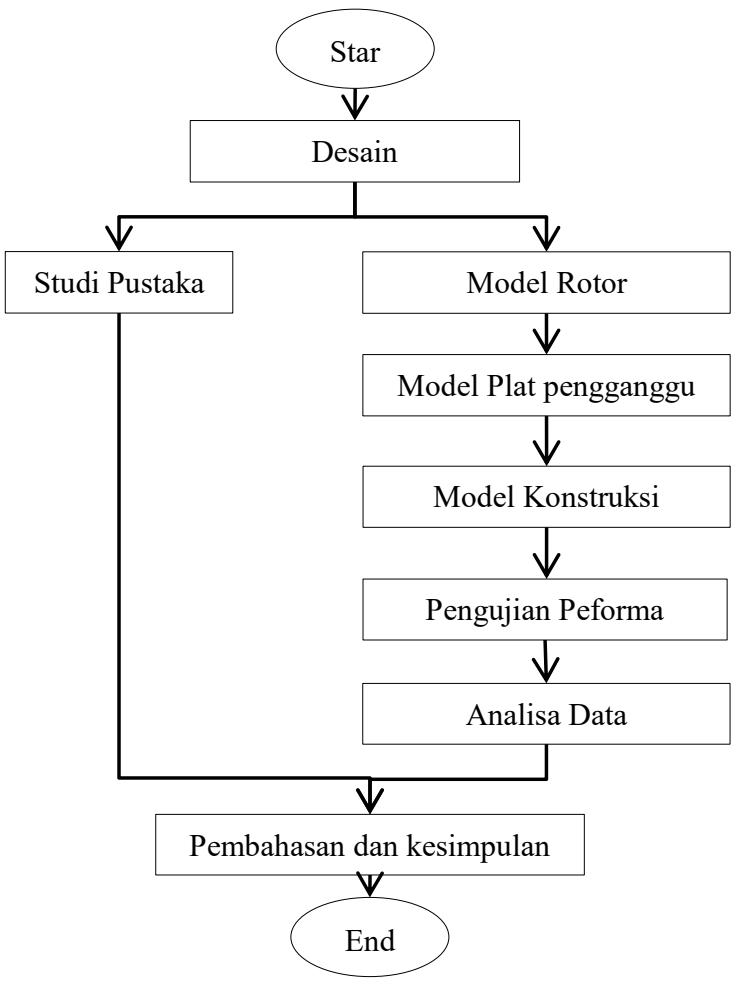

Gambar 1 Diagram alir penelitian

\section{Variasi Jumlah Sudu}

Untuk menguji peforma underwater rotor, dilakukan 3 variasi jumlah sudu yaitu sudu tiga, sudu 6 dan sudu 9. Pengujian dilakukan secara eksperimental

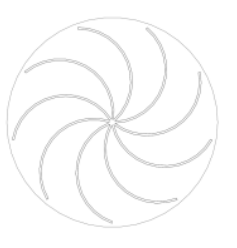

a

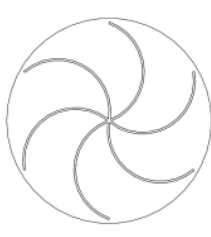

b

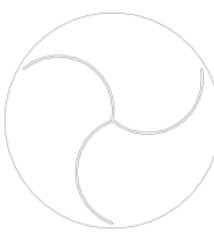

C
Gmabar 2. Variasi jumlah sudu (a) sudu tiga,

(b) sudu enam dan (c) sudu sembilan

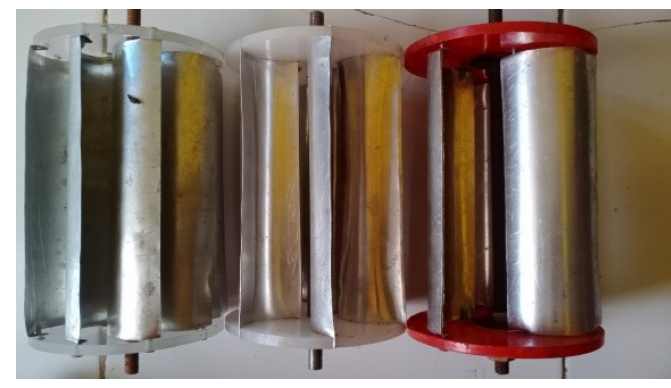

Gmabar 3. Foto sudu 3, sudu 6 dan sudu 9

\section{Pengukuran Torsi}

Dalam penelitian ini, metode yang digunakan untuk mengukur torsi adalah dengan metode pengereman mengacu pada penelitian penelitian terdahulu yaitu penelitian Mahmoud et.al (2020)

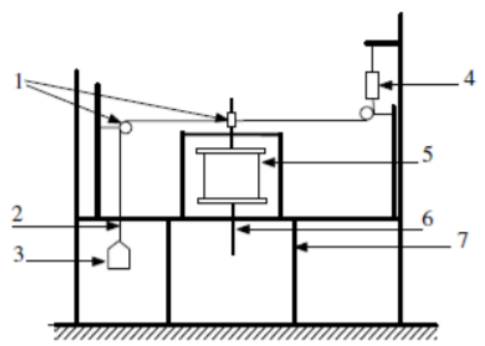

Gambar 4 Skema Pengukuran Torsi Mahmoud et.al (2020)

Prinsif kerjanya yaitu putaran turbin ditahan dengan memasang melingkatkan tali pada poros turbin kemudian tali tersebut dihubungkan dengan beban sehingga nantinya akan terbaca berapa besar beban yang mampu di purar turbin.

Dimana, torsi dapat dihitung dengan persamaan berikut 


$$
\tau=\{(s-m) g\} r
$$

Dimana, $\mathrm{S}$ adalah massa pada pegas, $\mathrm{m}$ adalah massa beban, $\mathrm{g}$ adalah grafitasi dan $\mathrm{r}$ adalah jari-jari tempat momen beban

\section{Kinerja rotor bawah air}

Kinerja rotor bawah air yang didesain dapat diketahui dengan melakukan perhitungan. Perhitungan-perhitungannya yaitu Tip Speed Ratio (TSR), Koefisien Torsi (CT) dan Koefisien Daya (CP).

\subsection{Tip Speed Ratio (TSR)}

Tip Speed Ratio (TSR) adalah rasio kecepatan ujung rotor terhadap kecepatan aliran air. Nilai TSR dapat dihitung dengan persamaan berikut (Purnama, A.C., Hantoro, R., Nugroho, G. 2013)

$$
\begin{aligned}
& T S R=\lambda=\frac{\omega R}{U} \ldots \ldots(2) \\
& \omega=\frac{2 \pi n}{60} \ldots \ldots \ldots . .(3)
\end{aligned}
$$

Di mana $\omega$ adalah menunjukan kecepatan sudut putaran turbin, $\mathrm{d}$ adalah diameter turbin $\mathrm{U}$ adalah kecepatan aliran fluida dan $\mathrm{n}$ adalah putaran.

\subsection{Koefisien Power ( $C p$ )}

Koefisien Power (Cp) adalah rasio perbandingan antara koefesien daya underwater rotor dengan daya total yang dihasilkan oleh fluida melewati underwater rotor Persamaan (4) merupakan koefisien power yang dapat dituliskan sebagai berikut. (Wenehenubun, F., Saputra, A., Sutanto, H., An, 2015)

$$
C p=\frac{T \omega}{\frac{1}{2} \rho U^{3} A} \ldots \ldots \ldots(4)
$$

Di mana $\mathrm{T}$ adalah torsi aktual, A adalah luas penampang rotor, $\rho$ merupakan massa jenis air.

\subsection{Koefesien momen (Cm)}

Koefesien momen $(\mathrm{Cm})$ adalah rasio perbandingan momen yang dapat dihasilkan oleh turbin dengan momen total yang dihasilkan oleh fluida melewati underwater rotor.

\section{Hasil dan Pembahasan}

\section{Desain Underwater Rotor}

Rotor bawah air adalah salah satu peralatan mekanik yang dapat mengubah energi kinetik aliran aliran air menjadi energi mekanik. Pada penelitian ini rotor bawah air yang didesain menggunakan tipe satu tingkat (single stage) tampa menggunakn poros anrata plat penutup (end plates) seperti yang ditunjukkan pada Gambar 5. (Kamoji, M.A., Kedare, S.B., Prabhu, S. V)

Pada penelitian ini untuk memperoleh kinerja rotor bawah air yang maksimal maka beberapa parameter yang adalah Aspect Ratio (H/D) 2; Blade shape factor $(p / q)=0,2$ dan diameter end-plate $=1,1 \mathrm{D}$. Penelitian dilakukan dengan menggunakan parameter desain turbin pada Tabel 1

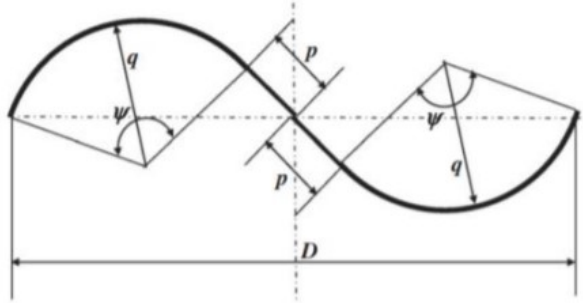

Gambar 5. Geometri Turbin Kamoji, M.A., Kedare, S.B., Prabhu, S. V

Tabel 1. Parameter Desain Underwater rotor

\begin{tabular}{cll}
\hline No & Parameter & Keterangan \\
\hline 1 & Aspect Rasio (H/D) & 2 \\
2 & Diameter End-plate & $110 \mathrm{~mm}$ \\
3 & Tebal End-plate & $5 \mathrm{~mm}$ \\
4 & Diameter Underwater rotor & $100 \mathrm{~mm}$ \\
5 & Tinggi Underwater rotor & $200 \mathrm{~mm}$ \\
6 & Tebal Sudu & $1 \mathrm{~mm}$ \\
\hline
\end{tabular}

\section{Plat Pengganggu}

Mengacu pada beberapa penelitian sebelumnya, pemasangan plat pengganggu di depan reaturning blade dapat meningkatkan peforma turbin. (Purnama, A.C., Hantoro, R., Nugroho, G., 2013). \& (Cengel Y, Cimbala, 2010)

Pemasangan plat pengganggun didepan rotor bawah air berfungsi untuk mengurangi gaya drag pada sisi cembung sudu dan pada sisi lainnya yaitu sisi cekung sudu akan 
mendapatkan aliran air yang leih banyak karena aliran air yang seharusnya mengarah ke sisi cembung sudu di arakkan langsung ke sisi cekung sudu sehingga memungkinkan selisih antara torsi negatif (sisi cembung sudu) dan torsi positif (sisi cekung sudu) lebih besar

Pada penelitian ini, desain rotor bawah air menggunakan plat penghalang dengan rasio $L / D=1.2 ; \Theta=0^{\circ} \leq \Theta \leq 90^{\circ}$. Seperti ditunjukan pada gambar 3. (Putra, Y, 2018) \& (Abadi, RP, 2018)

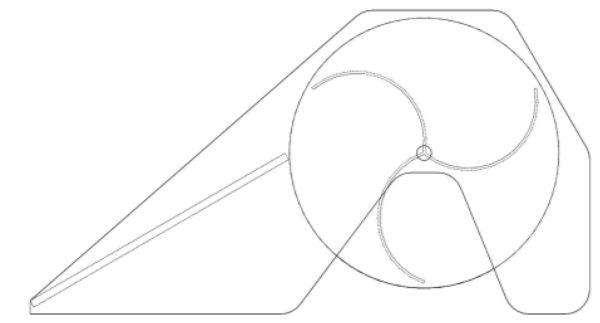

Gambar 6. Plat Pengganggu L/D $=1,2$ dan $\Theta \leq 60^{\circ}$

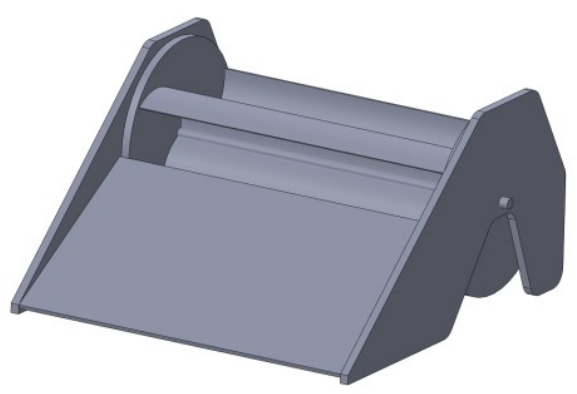

Gambar 6. Konstruksi Desain Rotor Bawah Air

\section{Pengaruh variasi jumlah sudu terhadap Koefesien tenaga}

Untuk mengetahui kinerja rotor bawah air yang sudah di didesain sebelumnya maka dulakukan pengujian yaitu dengan memvariasikan jumlah sudu yaitu sudu 3 , sudu 6 dan sudu 9 terhadap Tip Speed Ratio (TSR) pada pengujian ini yang diamati adalah perubahan nilai koefesien tenaga (Cp) yang mana koefesien tenaha (Cp) merupakan perbandingan antara energi yang diberikan oleh fluida dengan energi yang mampu di manfaatkan sudu

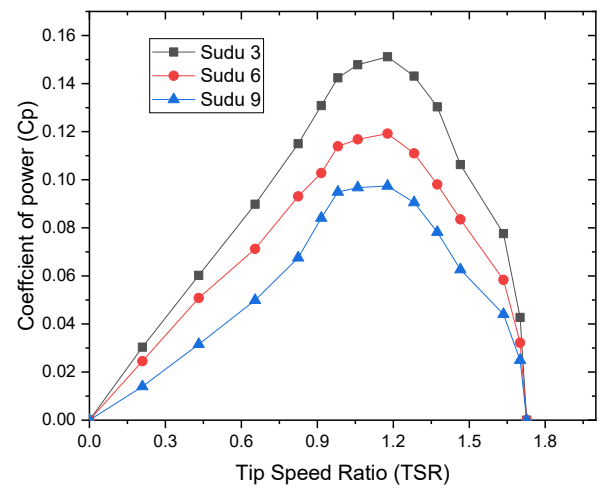

Gambar 8 Hubungan Antara Koefesien Tenaga dan Tip Speed Ratio terhadap variasi jumlah sudu

Gambar 8 merupakan grafik $\mathrm{Cp}$ terhadap Tip Speed ratio dengan variasi jumlah sudu. Pada grafik tersebut untuk variasi jumlah sudu 3 (tiga) didapatkan nilai $\mathrm{Cp}$ maksimum tertinggi adalah 0.151 pada TSR 1.178. sedangan nilia $\mathrm{Cp}$ maksimum terendah adalah 0.030 pada TSR 0.209. Untuk variasi jumlah sudu 6 (enam) didapatkan nilai Cp maksimum tertinggi adalah 0.11 pada TSR 0.92 . sedangan nilia Cp maksimum terendah adalah 0.025 pada TSR 0.183. Untuk variasi jumlah sudu 9 (sembilan) didapatkan nilai $\mathrm{Cp}$ maksimum tertinggi adalah 0.097 pada TSR 0.75 . sedangan nilia $\mathrm{Cp}$ maksimum terendah adalah 0.10 pada TSR 0.105 .

\section{Pengaruh variasi jumlah sudu terhadap Koefesien momen}

Untuk mengetahui kinerja rotor bawah air yang sudah di didesain sebelumnya maka dulakukan pengujian yaitu dengan memvariasikan jumlah sudu yaitu sudu 3 , sudu 6 dan sudu 9 terhadap Tip Speed Ratio (TSR) pada pengujian ini yang diamati adalah perubahan nilai koefesien momen $(\mathrm{Cm})$ yang mana koefesien tenaha $(\mathrm{Cm})$ merupakan perbandingan antara torsi dinamis dengan torsi yang dihasilkan turbin. 


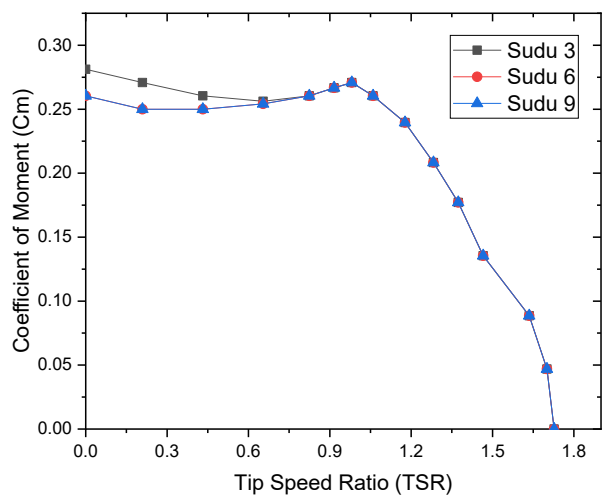

Gambar 9 Hubungan Antara Koefesien Torsi dan Tip Speed Ratio terhadap variasi jumlah sudu

Gambar 9 merupakan grafik koefesien momen $(\mathrm{Cm})$ terhadap Tip Speed Ratio (TSR) dengan variasi jumlah sudu. Dari gambar 9 dapat dilihat bahwa koefesien momen $(\mathrm{Cm})$ menurun saat terjadi peningkatan Tip Speed Ratio (TSR). Tip Speed Ratio (TSR) bibawah 0.9 cokefesien momen $(\mathrm{Cm})$ lebih besar dibandingkan dengan Tip Speed Ratio (TSR) diatas 0.9

\section{Kesimpulan}

Berdasarkan hasil penelitian dan analisa data bagaimana membuat desain underwater rotor untuk memanfaatkan laju aliran sungai sebagai pembangkit listrik tenaga air dapat di ambil beberapa kesimpulan sebagai berikut :

1. Desain rotor bawah air dengan Aspect Ratio $(H / D)=2$; Blade shape factor $(p / q)=$ 0,2 dengan Overlap ratio $=0$ dan diameter end-plate $=1,1 \mathrm{D}$. menggunakan plat penghalang dengan rasio $L / D=1.2$; $\Theta \leq$ $60^{\circ}$. Dapat digunakan untuk pembangkit listrik tenaga aliran sungai.

2. Jumlah sudu berpengaruh terhadap koefesien tenaga $(\mathrm{Cp})$ dan koefesien torsi $(\mathrm{Cm})$. Desain rotor bawah air dengan jumlah sudu 3 (tiga) memberikan nilai Cpdan $\mathrm{Cm}$ tertinggi berturut-turut yaitu 0.15 dan 0.27 pada TSR dibawah 0.9

\section{Daftar Pustaka}

Cengel Y, Cimbala.,(2010). Fluid Mechanics: Fundamentals and Applications, 3rd ed. McGraw-Hill Companies, Inc., New
York, NY. Boston: McGraw-HillHigher Education;. p 854.

Kamoji, M.A., Kedare, S.B., Prabhu, S. V, (2009). Experimental Investigations on Single Stage Modified Savonius Rotor. Applied Energy. 86(7-8): p. 1064-1073 .

Putra, Y. (2018). Pengaruh Jumlah Sudu terhadap Unjuk Kerja Kincir Air Poros Vertikal Tipe Savonius. Yogyakarta: Universitas Sanata Dharma. P.53.

Purnama, A.C., Hantoro, R., Nugroho, G., (2013). Rancang Bangun Turbin Air Sungai Soros Vertikal Tipe Savonius dengan menggunakan Pemandu Arah Aliran. JURNAL TEKNIK POMITS. 2(2): p. 278-282

Rendi, R. (2017). Analisa Distribusi Tekanan Dan Aliran Disekitar Rotor Savonius Water Turbine. 02(02), 108-113.

Rendi, R., \& Arifin, J. (2019). Desain Diffuser Turbin Air Arus Sungai Untuk Meningkatkan Laju Arus Sungai. AlJazari Jurnal Ilmiah Teknik Mesin, 4(2), 62-66. https://doi.org/10.31602/aljazari.v4i2.2645

Rendi, R., Arifin, J., Mujiburrahman, M., \& Trianiza, I. (2020). Potensi Pembangkit Listrik Tenaga Air Mikrohidro di Sungai Pintab dan Sungai Amandit Kalimantan Selatan. Jurnal Engine: Energi, Manufaktur, Dan Material, 4(2), 46-52. https://ejournal.up45.ac.id/index.php/Jurn al_ENGINE/article/view/733

Rendi, R., \& Hartadi, B. (2018). Pengaruh Penambahan Nozzle Guide Vane Pada Rotor Savonius Modifikasi Untuk Turbin Air. Al-Jazari Jurnal Ilmiah Teknik Mesin, 3(1), 74-79. https://doi.org/10.31602/aljazari.v3i1.1396

Rendi, R., Ihsan, S., \& Ma'arif, S. (2020). Turbin Air Arus Sungai Model Sudu Propeller Menggunakan. 4(1), 27-33.

Rendi, R., \& Sidiq, A. (2018). Pengaruh Twist Angle Blade Turbin Savonius Berpengarah Aliran Aplikasi Pada Turbin Air. Info-Teknik, 19(2), 203. https://doi.org/10.20527/jit.v19i2.154 
Jurnal Engine: Energi, Manufaktur, dan Material

Rendi, Hatradi, Irfansyah \& Puteri, Vol. 5, No. 2, 2021: 77-82

Rendi, R., \& Herlina, F. (2019). Penambahan Lingkaran Pelindung Pada Turbin Air Rotor Savonius. Info-Teknik: Jurnal Keilmuan dan Aplikasi Teknik, 20(2), 237-254.

doi:10.20527/infotek.v20i2.7720

Wenehenubun, F., Saputra, A., Sutanto, H., An, (2015). Experimental Study on the Performance of Savonius Wind Turbines Related with the Number of Blades. Energy Procedia.p. 297-304. 